\title{
The Result of Developing Secondary School Students' Public Conscience through Process-Knowledge Management in Thailand
}

\author{
Nawattakorn Homsin ${ }^{1}$, Chalard Chantarasombat ${ }^{1} \&$ Theerawatta Yeamsang ${ }^{1}$ \\ ${ }^{1}$ Faculty of Education, Mahasarakham University, Thailand \\ Correspondence: Nawattakorn Homsin, Faculty of Education, Mahasarakham University, Thailand. Tel: \\ 66-89-864-4528. E-mail: nawattakorn@hotmail.com
}

\author{
Received: November 5, 2014 Accepted: February 5, 2015 Online Published: June 29, 2015 \\ doi:10.5539/ies.v8n7p240 URL: http://dx.doi.org/10.5539/ies.v8n7p240
}

\begin{abstract}
This research uses Mixed-Methodology applied research and development together with participatory action research. The model is appropriate for the context environment. The participants were able to complete the learning activities in participatory forms of knowledge management, using the following five-step model: 1) Knowledge Identification 2) Knowledge Creation 3) Knowledge Preservation 4)Knowledge Sharing and 5)Knowledge Application. Action research involved 7 main activities down to the operating activities, thus developing public participation in 15 sub-activities.
\end{abstract}

Keywords: knowledge management, participatory action research, public conscience, action learning

\section{Introduction}

\subsection{Introducing the Problem}

Public Conscience refers to a consciousness of correct behaviour. With regard to collective sharing, knowing empathy is engaged in the collective interest of the nation, leading to a sense of ownership in what is communal. The resulting realization and action lead to willingness, without being told, to have a certain (correct) attitude; this does not involve anyone being ordered and it is not orchestrated. On the contrary, it is due to a desire to make things better in Thailand today (The development and political participation, 2010). This attitude has been an important feature of the past. However, children in society today take no responsibility for themselves or for others. In addition, there are social problems such as stealing, theft, muggings-expressions of selfishness.

We have developed and adopted attitudes for Public Conscience to implement the National Education Act 1999, Section 7 providing the appropriate purpose and process of learning, thus to focus awareness on the correct attitudes for the learner (Ministry of Education, 2008). The development of human resources for individuals of all ages to develop their own potential is endless. So a Public Conscience is a desirable feature of learners, and is an important goal for educators; it must be established as a primary issue. To achieve these outcomes, it is necessary to set goals and directions for the study, together with other elements that promote, support, and manage studies conducted in the right directions, while responding to social development and pace, leading the world in the era of the knowledge economy (Sinraratana, 2006)

\subsection{Exploring the Importance of the Problem}

The development of students' public conscience is very necessary and important because one of the factors of National Major Power is human resources. For national development to be prosperous in every aspect, it is indispensable to inculcate virtue and morality in the children and youth of the country since, when the grow into adulthood, they would then be of good quality and ethics. Thus a basis is formed for efficient socialization through social institutions including the family, educational institutes and religious institutes. Therefore, the development of a public conscience is very necessary. Every sector has to participate in its development. This development can be performed in concrete as well as sustainable forms. With community participation in decision making as well as development, the community would feel that they are owners, and there is a partnership. This technique would be the way leading to sustainable development (Tongho, 2008).

Participation of all parties involved in the development of the Public Conscience of the learner will require tools that can be used to develop people. Current society, which today is called 'Social Knowledge Base', relies on three factors: the response-driven knowledge, creation and experience however when entering the knowledge 
society, we will build on the knowledge-driven society with trusting, caring, sharing, and collaborating. The desire for existence in the knowledge society continues with the attributes of meaningfulness and happiness to be added to the morality and ethics of society. Mabintree (2007) has mentioned the idea that knowledge is a valuable resource. Then the development of new knowledge to compete and strengthen is needed. The basic is crucial to the development process which discusses this tool as knowledge management which uses the concept of participation of members of the organization. Mobilize the existing knowledge to develop a system effectively (Office of Secretariat, Council of Education, 2010), and the principle is the same concept of participatory action research (participatory action research), which uses the concept of participation. In addition, collaborative planning together with work practice observed - reflect the performance.

\subsection{Describe Relevant Scholarship}

This study focused on activities to be used to develop public or development courses. For example, simulation through comic role models. Story telling through puppets and models that symbolize a small textbook. It was found that there are two factors influencing the public conscience: external factors and internal factors. The spirit within the individual's influence on the individual level affects the public conscience. We conclude that the development of knowledge and morality, sacrifice and dedication to the common good, are desirable to help solve problems for others and for society as a whole.

So, knowledge is an important thing in every step of human life, and valuable in every organization. Consequently, educational institutions are the places where everyone has to attain and build upon knowledge. Knowledge management as the role model for individuals, groups and organizations (Office of Secretariat, Council of Education, 2010). Knowledge is a broad and abstract notion that has defined epistemological debate in western philosophy since the classical Greek era. In the past few years, however, there has been a raging interest in treating knowledge as a significant organizational resource. For example, some companies have started to produce supplemental annual reports reflecting their intellectual and knowledge assets, while others have created the organizational position of Chief Knowledge Officer. The heightened interest in organizational knowledge and knowledge management is primarily motivated by the transition into the knowledge economy, where knowledge is viewed as the principle source of organizational rent and sustainable competitive advantage (Alavi \& Leidner, 1998). Knowledge Management is an instrument for tapping the inherent potential. It is useful in many dimensions by drawing forth tacit knowledge in human beings, construct, and apply knowledge and experience for knowledge or innovation, and store it as an information source which could be accessed by the persons from different channels organized by organizations so that existing knowledge would be applied in developing work, human endeavours, and organization (Chantarasombat, 2010).

\subsection{The Hypothesis and Its Correspondence to Research Design}

Researchers who are involved in the development of education and are interested to participate in the development of students achieve desirable features, especially the Public Conscience as a series of knowledge caused by practice. For this study, the knowledge obtained will be used to develop a desirable feature. Both attribute their common features and features to learn and discover patterns and processes of development appropriate to the context of education. This development will enhance the quality of students and of higher education in Thailand. Another part of the research suggests that knowledge management is a process that produces new knowledge which can develop students to possess the Public Conscience and discover a model developed in the Public Conscience with learning through best practice. Additionally, the new knowledge can be appropriately applied to schools that have the same context.

\section{The Purpose of the Study}

The purposes of the study were: 1) to study the results of developing secondary school students' public conscience through a process of knowledge management in Thailand. And 2) to assess satisfaction with knowledge management for developing secondary school students' public conscience in Thailand.

\section{Methodology}

The data were collected according to the knowledge obtained from the workshops organized by the research team at five secondary schools in Northeastern of Thailand about 10 times. The research participants included 14 teachers, 9 students and 9 administrative staff. The study was divided into 7 phases:

Phase1. Analysis of Problems and Needs: Workshop must be participatory and constructive. The Application of Analysis Problem Tree was used. The cause of the problem, the root of the problem, and ranking the importance of the issue were used for brain storming to determine the topics to be collected. At this stage, 654 students were answered the questionnaires then these resulting data will be used for Phase 2. 
Phase 2. Creation of Motivation and Awareness: The meeting to share their opinions on activities focusing on the needs of students in three parts: 1) the desire to start a fun activity, 2) the need to do things with friends, and 3)the need to do things to benefit others. Whatever comes to their notice. Implementation of activities, learning and development of their participation in the preliminary stage to participate willingly in the action plan developed public conscience of the student. School students and teachers study the development of desirable attributes

Phase 3. Establishment of Developmental Plan and Innovation: Development within the research team and prepare knowledge-management plans, thus to develop appropriate secondary school students' public conscience the appropriate. In particular the concept of Nonaka and Takeuchi (1995), Panich (2005) and Chantarasombat (2007). The concept of Action Learning of Chantarasombat (2008). The concept of Social Cognitive Learning Theory Banduru (1977). The concept of Participatory Action Research of Ramasoota (1997) and Chantarasombat (2008). The concept of Desirable characteristics development of Wongvanich (2009). And survey results the school's with outstanding promotion activity and development of public affection. To build knowledge management model for developing secondary school students' public conscience in Thailand. Then take the model of KM model temporary for developing secondary school students' public conscience in Thailand. And development plans secondary school students' public conscience. Experts offer 5 to determine the appropriate action. To consider 1$)$ the model is reasonable $\left(\mathrm{X}^{-}=4.51\right)$, possibility $\left(\mathrm{X}^{-}=4.59\right)$, consistency $\left(\mathrm{X}^{-}=4.57\right)$, and useful $\left(\mathrm{X}^{-}=4.54\right)$, with the average at the highest level, and 2) development plan. Public conscience are reasonable $\left(\mathrm{X}^{-}=4.57\right)$, possibility $\left(\mathrm{X}^{-}=4.53\right)$, consistency $\left(\mathrm{X}^{-}=4.54\right)$, and useful $\left(\mathrm{X}^{-}=4.64\right)$, with the average at the highest level. Can synthesize Action learning and KM process into 5 steps process and participatory action research 7 steps. The development tools includes 1) Achievement test in KM with the discriminative between $.317-.779$ with the reliability of the original $.812,2$ ) test of knowledge about the development of public conscience discrimination between $.256-.901$ with a reliability .863 and the assess success of KM discrimination between $.443-.877$ with a reliability .825 .

Phase 4. Individual Construction: Researcher and co-researchers has conduct workshops and participate constructively. The brainstormed suggestions of the team. Indicators of success in the event. Guide the implementation of the public conscience. Defines indicators of success of the event whole the third consists of the features involved. Are indicators of success of the event 5 on 25 indicators of the attribute? Are indicators of success of the event 4total of 29indicators and aspects of learning? Is indicators of success of the event 4 on 37 indicators, and later presented the thesis shall be presented to the 5experts consider the consistency between activities and indicators of success. The evaluation result are based on an average at high level $\left(X^{-}=4.11\right)$ and together create a plan manual implementing the public mind development of secondary school students. Which have passed luminaries as 3 attributes are reasonable $\left(X^{-}=4.86\right)$ possibility $\left(X^{-}=4.88\right)$ useful $\left(X^{-}=4.98\right)$ and consistency $(X=4.85)$ at the most.

Phase 5. Conducting experiments using planning: Temporary secondary school students and action plan development activities of the secondary school students' public conscience. The instrument used to collect the data base. A semi-structured interview, the unstructured interview, participant-observation, observation-form does not participate. Before Action Report: BAR. Within Action Review: WAR. After Action Report: AAR. The evaluation result of experts has an average level. There are two elements essential elements: 1) the action research participation seven steps, and 2) the activities of public conscience development of students participatory as 14 sub-activities.

1) Creative Participatory Workshop

2) Teamwork Development.

3) The Study of the Needs to Participate in the Activities

4) The Field Trip Study to Schools with Best Practice.

5) Planning for Development in Team

6) Establishment of Appropriate Plan for Developing.

7) Brainstorming Workshop in the Team

8) Establishment of Indicator of Success

9) Establishment of Handbook for Implementation.

10) Implementation according to the plan for implementing activities as well as evaluation

11) Conference for sharing one's opinion 
12) Analysis, synthesis, and investigation of implementation.

13) Evaluation and success of implementation according to plan was concluded.

14) Practice for Sharing

Phase 6. Evaluation: The researcher and co-researchers sharing, analysis, synthesis and verification after the activities to assess progress on within action review: WAR. Presents the results of knowledge management. The framework in action is to assess the power of a target three factors: (1) the development process aimed at developing a better evaluation. To learn, to change, (2) responsibility is to consider, consider, and (3) the creation of knowledge. Value the knowledge arising from the project together. A community of learning. The knowledge and wisdom to change. And assessment after treatment using a technique based on the use of assessment centers assessment plan to measure success. And monitoring and evaluation of the school's co-research team.

Phase7.Sharing: The researcher and co-researchers in the conclusion of the activities. Exhibitions showcase the public conscience of students in school groups. The activities to develop students' public conscious as to the purpose of the research. Students or schools have the opportunity to bring their work, representing problem solving. The data presented in www.nawattakorn.com and www.drchalard.com and presentation on 8th International Forum on Knowledge Asset Dynamics, Zagreb, Croatia 12-14 June 2013, on the theme of Smart Growth: Organizations, Cities and Communities.

\section{Conclusions}

\subsection{Results for the Developing Secondary School Students' Public Conscience through a Process Knowledge Management in Thailand}

Is appropriate to the context environment. The participants were able to perform the activities of learning, participatory forms of management knowledge includes 1) Knowledge Identification 2) Knowledge Creation 3) Knowledge Preservation 4) Knowledge Sharing and 5) Knowledge Application. The implementation of the plan and improving the After Action Report: AAR. Can be summarized as follows:

\subsubsection{Knowledge Identification}

The group wanted to develop students' characteristics by emphasizing the student-centered approach. The activities should cause self-development and development of community, society. Learning should take place individually and publicly without increasing an extra workload. Activities should be practiced daily by students through collaboration in designing the process of implementation by teachers, and students.

\subsubsection{Knowledge Creation}

Before implementation, the group consisted of staff who advised in developing personal and public characteristics, and learning. The activities were those which the students should be familiar with by collaboration in designing the process of shared implementation by teachers, and students. Before action, the group had staff who advised in developing personal and public characteristics, and learning. Activities were those which students should be familiar with but there was no grouping together, continuous development, and transference from one generation to another. After implementation, each one studied the activities of different schools via field trip, Internet, and various printed material. When students participated in group, they shared knowledge starting from determination of activities, collaboration in planning for implementation and fashioned assignment of responsibility, evaluation. The group members tried to work in a step-by-step manner. This way they could develop personal characteristics of group members leading to development of the group on one level.

\subsubsection{Knowledge Preservation}

The knowledge report was established for development of personal characteristics including 5 activities. Activities for public development 5. And the development of learning characteristics 4 activities.

\subsubsection{Knowledge Sharing}

Teachers and students collaborated in observing students' behavior and their own color group. They collaborated in concluding notices from students' record form, and suggesting, and designing, and finding better guidelines. They shared their knowledge with group members with similar characteristics, and those outside the group. Besides, there was a sharing among La-tai-wittaya School, Yamngchoomnoi-pittayakom School, Prasanmit-wittaya School, and Bua-noi-wittaya School.

\subsubsection{Knowledge Application}

The group obtained knowledge in developing students' public conscience regarding personal characteristics, transference for members as well as other interested parting, being able to transfer to other youths. The students 
were another body of knowledge, able to practice by themselves, and bring the process obtaining from sharing to improve, develop, and apply continuously as well as conclude the findings periodically. The information was improved, corrected, changed, and applies for use in development for follow up, help, correction, and the encouragement of students on a more correct basis.

The results for the developing secondary school students' public conscience through a process knowledge management in Thailand found that the research participants were able to implement the activities for developing participatory public conscience. The self-development and development of school and community included: 1 ) the ability to participate in activities of development in public at highest level, 2) the practice of activities for developing one's behavior according to the indicators of success for developing one's public conscience leading to actual practice at "very good" level, and 3) knowledge management model for developing secondary school students' public conscience, was practical and noteworthy for 2 major factors: the 7 steps of participatory action research, and implementation in organizing participatory public conscience in integrated implementation including shared thinking, decision making, practice, responsibility, benefit, and conclusion in 15 sub-activities as shown in Illustration 1.

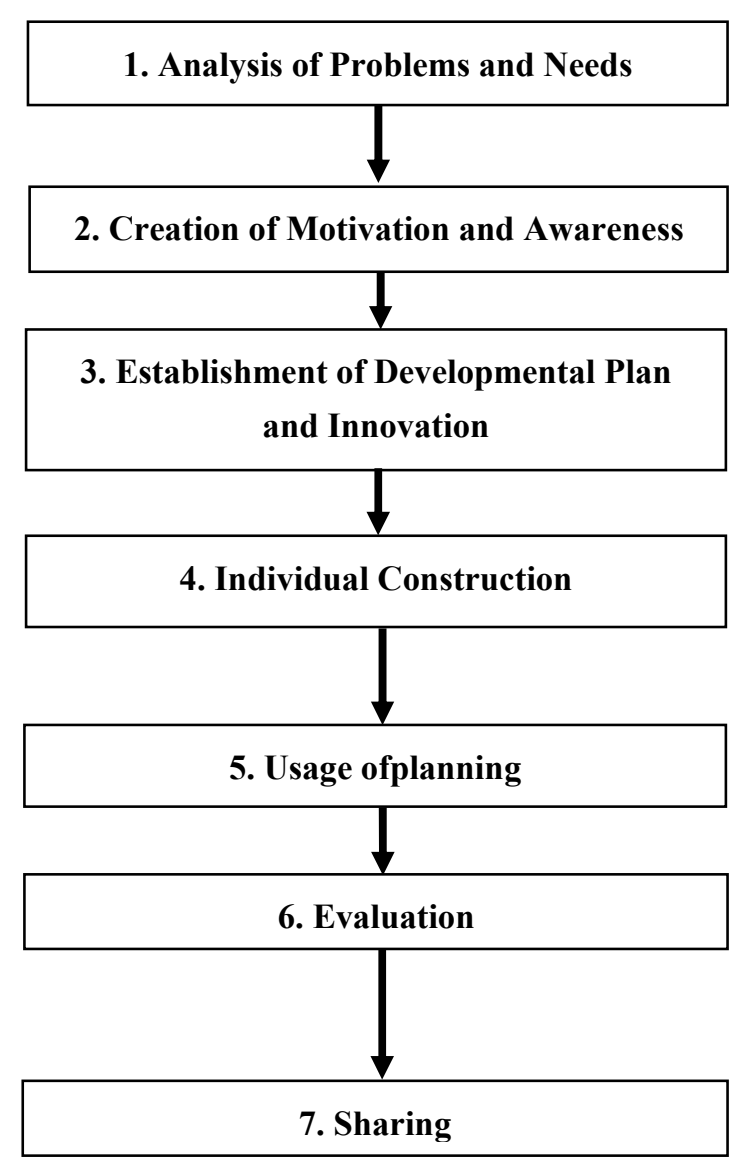

- Creative Participatory Workshop

- Teamwork Development

- The Study of the Needs to Participate in the Activities

-The Field Trip Study to Schools with Best Practice

-Planning for Development in Team

-Establishment of Appropriate Plan for Developing

-Brainstorming Workshop in the Team

-Establishment of Handbook for Implementation

-Establishment of Indicator of Success

- Implementation according to the plan for implementing activities as well as evaluation

- Conference for sharing one's opinion

- Analysis, synthesis, and investigation of implementation

-Evaluation and success of implementation according to plan was concluded

-Practice for Sharing

-Presentation of Performance

Illustration1. The developing secondary school students' public conscience through process-knowledge management in Thailand

It was also found that:

(1) The research participants were the work practitioners, note takers, and group co-operators of all 3 groups, including knowledge management, origin of knowledge obtained from problems, questioning, and problem solving by real practice till the appropriate body of knowledge as well as success in group implementation was achieved

(2) The research participants had learning processes from the source-of-knowledge specification and 
construction, organization of knowledge management, knowledge sharing and application.

(3) The research participants collaborated in integrating their own knowledge with new knowledge. There was adequate and congruent knowledge with the needs of students, school, and community including: 1) the administration and management, 2) the knowledge management center for the group to share their knowledge both internally and externally via website, and 3) there were knowledge package and work pieces of research participants.

4.2 Assessment of the Success of Knowledge Management Developing Secondary School Students' Public Conscious in Thailand

Use satisfaction with knowledge management of participants. Assess both at the personal level, group level, and the organizational level. See Tables 1-3.

Table 1. Assessment of satisfaction with the implementation of knowledge management, personal level

\begin{tabular}{|c|c|c|c|c|}
\hline No. & Indicators & Personal & Public & Learning \\
\hline 1 & Awareness of importance learning. & 4.43 & 4.37 & 4.16 \\
\hline 2 & $\begin{array}{l}\text { Enthusiasm pursues knowledge and learning and ready to learn throughout } \\
\text { life. }\end{array}$ & 4.23 & 4.35 & 3.99 \\
\hline 3 & The Systems Thinking creative & 4.35 & 4.35 & 4.00 \\
\hline 4 & Responsibility for their own learning continuously. & 4.36 & 4.52 & 4.21 \\
\hline 5 & $\begin{array}{l}\text { Works or parts of their proudest contributions to Share \& Care of group } \\
\text { membership. }\end{array}$ & 4.35 & 4.44 & 4.22 \\
\hline 6 & Recorded after their performance continuously. & 4.31 & 4.51 & 4.18 \\
\hline 7 & Using Technology And Innovation in Practice & 4.51 & 4.48 & 4.09 \\
\hline 8 & $\begin{array}{l}\text { Guide the implementation of knowledge management in the public } \\
\text { conscience, to develop operational efficiency. }\end{array}$ & 4.48 & 4.47 & 4.47 \\
\hline 9 & To learn new things. & 4.35 & 4.52 & 4.21 \\
\hline \multirow[t]{2}{*}{10} & Experience in knowledge management Action learning. & 4.35 & 4.37 & 4.30 \\
\hline & Total & 4.37 & 4.44 & 4.18 \\
\hline
\end{tabular}

Table 2. Assessment of satisfaction with the implementation of knowledge management, group level

\begin{tabular}{lllll}
\hline No. & Indicators & Personal & Public & Learning \\
\hline 1 & Creating a vision for a common goal. & 4.54 & 4.43 & 4.31 \\
2 & Team building through training, workshops and study tours. & 4.18 & 4.23 & 4.21 \\
3 & Participatory planning to put it into practice. & 4.44 & 4.35 & 3.94 \\
4 & Encourage group activities And teamwork & 4.47 & 4.36 & 4.46 \\
5 & The implementation and development tasks. & 4.50 & 4.37 & 4.15 \\
6 & Responsibilities in their assignments. & 4.71 & 4.49 & 4.37 \\
7 & Creating new knowledge Then Share \& Care among group members. & 4.63 & 4.27 & 4.23 \\
8 & Send to performance continuously. & 4.51 & 4.54 & 4.37 \\
9 & To learn to work as a team. & 4.51 & 4.29 & 4.11 \\
10 & Gain experience in learning the practice team. & 4.51 & 4.37 & 4.29 \\
& Total & 4.50 & 4.37 & 4.24 \\
\hline
\end{tabular}


Table 3. Assessment of satisfaction with the implementation of knowledge management, organization level

\begin{tabular}{lllll}
\hline No. & Indicators & Personal & Public & Learning \\
\hline 1 & Environment that promotes learning. & 4.50 & 4.38 & 4.28 \\
2 & Creating a culture of learning that occurs. & 4.20 & 4.46 & 4.52 \\
3 & Developing people in the organization to its full potential. & 4.34 & 4.27 & 4.46 \\
4 & Information system for continuous improvement. & 4.44 & 4.41 & 4.43 \\
5 & Defining metrics down to the success of the organization as a goal of & & & \\
& development. & 4.36 & 4.43 & 4.43 \\
6 & Tracking system Audit Practice & 4.53 & 4.51 & 4.48 \\
7 & Knowledge is a collection of research articles. Or innovative learning of & & & \\
& team participants. & 4.52 & 4.40 & 4.48 \\
8 & Schools are educating on issues of interest. And storing a wide range of & & & \\
& knowledge. & 4.47 & 4.46 & 4.51 \\
9 & Schools have their own identity management proper knowledge. & 4.33 & 4.44 & 4.50 \\
10 & School as a learning organization. & 4.33 & 4.36 & 4.40 \\
& Total & 4.40 & 4.41 & 4.45 \\
\hline
\end{tabular}

The tables show that the assessment of satisfaction in the implementation of knowledge management at personal group level and the organizational level. In terms of personal characteristics attribute and Learning Features Overall, the high level the results of the assessment was a participatory action research (PAR) was achieved based on indicators. Success and set goals. This is due to the following factors.

1) The researcher and co-researchers as a learner a coach Executive management and the external power. Stimulation provokes action, participatory and sustainable. The researcher calling themselves Knowledge Facilitator: KF.

2) The importance of knowledge management. When conducting research in the final. The Research Team is committed to working to fulfill public roles. This research consortium, which is called the context of the school. Classified as follows:

(a) This facilitates the implementation of the research is the management of the knowledge management system of the organization. Target and associated goal of knowledge management with the vision, mission and strategy of the organization. Keep monitoring and implementation of knowledge management seems to appreciate some advice to show interest. Including the award could not focus on the object but focus on building pride in success. Share their skills to learn. Skills and knowledge. For the sake of Direct implementation of knowledge management, the school director and chairman of the board of education. In this research, called Chief Knowledge Officer: CKO.

(b) The director is the permitting knowledge is responsible for managing the knowledge in question. Not say or show that knowledge out. To share with other members. The group has a role as an extra power. Learning process by agreement. The researcher calling themselves Knowledge Facilitator 1: KF1.

(c) Worker group, or your work will be the implementation of knowledge management is considered to be about 90 percent of all managers know it. Is a common target achievement of the group. Those who have Explicit Knowledge and who must want to learn the knowledge, knowledge creation, knowledge and the translation of knowledge to practice to achieve the "target" set, in which the researchers called. Knowledge Practitioner: KP.

(d) You mean those scripts to serve the knowledge gained from the narrative Tacit Knowledge, Explicit Knowledge is written. Joint study of current issues, planning, implementation, monitoring and accountability, but also the secondary function is. Record the information in the knowledge of the Officers and members of the voluntary participants. In ongoing research In this research, called Knowledge Partitioned.

(3) Coordinator will act as liaison between the networks of knowledge management features. Or between school and community for those who have been the trust of the Party of network management. That can provide coordinated network. In this research, called Network Manager.

3) Opportunity for participants to take part from the beginning, contemplate, planning practices, monitor and 
co-responsible for the conduct of research. An important factor to do would be to own a network of knowledge management. The initiative's vision of participatory activities. Management Continuity and obligations to be performed manually on completion of projects affecting love each generosity.

\section{Discussion}

\subsection{The Developing Secondary School Students' Public Conscience through a Process Knowledge Management in Thailand}

Rewires learning the process of knowledge management in 5 step action research. Participatory 7 steps down to the operating activities develop public participation activities and outcomes of the model 15-17 elements forming a successful fruition as expected. This is due to the development of a research framework to analyze, synthesize concepts and findings of a panel of international experts. Knowledge management and development techniques as Jennex and Zakharova (2005) KM is the process used to make knowledge actionable to members of the organization. It involves capturing, storing, retrieving and using knowledge. KM involves the creation of a KM system. The KM system includes an environment that promotes organizational learning. In this respect KM can be an organizational change or transformation tool as it can help management create a learning organizational culture. $\mathrm{KM}$ is a tool for improving organizational effectiveness as it promotes knowledge reuse to improve decision making. such as using knowledge management concepts are applicable to Nonaka and Takeuchi (1995), Panich (2005) and Chantarasombat (2007) action learning of Chantarasombat (2008), together with other principles such as taking notes after practice (AAR), questioning, real and virtual knowledge exchange, Attributed to the mechanisms underpinning knowledge management is knowledge management in schools, both as a source of action and on the Web. This enables the management to develop the public's knowledge of secondary school students and some evidence that indicates the success it has brought criticism.

\subsubsection{Participation Is the Key to Learning}

All features have the knowledge to develop the public five group manager Chief Knowledge Officer: CKO Knowledge Facilitator: KF Knowledge Practitioner: KP Note Taker and Network Manager. This is in accordance with Nonaka and Takeuchi (1995), team building, knowledge management, starting at the individual mind. Group members understand the role of knowledge management is that managers are aware that a major operational staff. Group of middle managers as they interpret convert knowledge into knowledge on paper. Knowledge Management Group Acts targeting create an atmosphere conducive to the exchange of knowledge and to extract value. Our finding was in consistent with the report of Panich (2005), that the key knowledge management in your organization, including a director who fosters the exchange of knowledge in the activity and cultural systems. You work as a worker group considered as a knowledge management activity or about 90 percent of all your notes, information on events destined as a knowledge management narrative summary of core knowledge. Meeting notes and coordination co-ordination network acting is considered as a knowledge management and enterprise groups.

5.1.2 Learning Coupled with Practical Knowledge of the Source of the Problem, Questioning the Practicality and the Solution with the Right Knowledge

Contribute to knowledge management issues. Interested consists Identifying knowledge creation the knowledge of the system. Knowledge exchange and application of knowledge. American pragmatism result individuals not only require having a base of abstract concepts and principles, but putting them into action. Then we should see the "Knowledge as a tool at service of not knowing something that once possessed" (Cook \& Brown, 1999), consistent with Wijan (2007) stated that the process of knowledge management as a major activity to be developed to leverage the intellectual capital of the organization, which is higher. Resources can cause worth and value to the organization as much as possible consistent with Prawet (2002) said that learning of one person is not enough to make it successful, because other people and organizations. Institutions have not learned. Learning together in practice only to yield successful results, which must manage the knowledge through a series of practical knowledge of each organization in line with Phaynoi (2003), who said that the record after practice. (AAR) is an important learning to extract the essence of knowledge. Findings of the individual or organization that is roughly consistent with Sangkeap (2012) that said AAR as a tool to analyze the practice to improve and develop work practice echoed back immediately. pass This is a way to cause learning during the implementation and development of people. Development of projects is consistent with theories of social learning oriented rationality (Social Cognitive Learning Theory) of Albert Bandura (1977) believed that the experience of social thought to play a role in the development and modification of behavior by the child. Learn new behaviors, which raised him to act grown up. By imitating parents which may cause positive behavior. It has been awarded as the reinforcement. And consistent with Chantarasombat (2008) that said, learning from practice. Together with other 
measures, such as AAR, the question of knowledge, both the real and the virtual. Moreover, the mechanisms underpinning knowledge management is a knowledge management in schools. As a source of action and in the Web, (www.drchalard.com) contribute to knowledge management.

\subsection{Assessment of the Success of Knowledge Management Developing Secondary School Students' Public} Conscious the Successful Operation at the Moment

Due to contemplate, decided to conduct a joint responsibility. Join beneficiaries and finalized with Both at the personal level, group level, and the organizational level. With the teacher. School board parents and students have resulted in the developing of students' public conscious. Successful this is due to the work by the planning system. Carefully prepared performance through participation. The results of the use, including monitoring performance periodically. Knowledge management success can be viewed as an outcome measure. Knowledge management success is therefore seen as a measure of the various outcomes of knowledge process capabilities existing within an organization as a result of undertaken Knowledge management initiatives. Typical outcomes in terms of organizational performance are the enhancement of: 1) product and service quality, 2) productivity, 3) innovative ability and activity, 4) competitive capacity and position in the market, 5) proximity to customers and customer satisfaction, 6) employee satisfaction, 7) communication and knowledge sharing and 8) knowledge transparency and retention (Jennex, and Smolnik.2011).Which corresponds to Ramasoota (1997) whose ideas about the research participant has 9 steps: 1) community, 2) training researchers together from the community, 3) determining the research model 4) embarked storage 5) processing and analysis 6) discussing findings with the community 7) planned community 8) leads to action plans and 9) monitoring and evaluation in the community. The concept of Chantarasombat (2009) has 5 steps: 1) preparing community 2) motivating consciousness. And promoting participation and create a vision 3) the plan development team 4) the plan development and implementation, and 5) evaluation.

\section{Acknowledgements}

The researchers would like to express our thanks and gratitude to Faculty of Education, Mahasarakham University, Thailand for financial support for this research paper.

\section{References}

Alavi, M., \& Leidner, D. E. (1998). Knowledge Management and Knowledge Management Systems: Conceptual Foundations and an Agenda for Research. Fontainebleau, France: INSEAD.

Alavi, M., \& Leidner, D. E. (2001). Review: Knowledge Management And Knowledge Management Systems: Conceptual Foundations And Research Issues. MIS Quarterly, 25(1), 107-136. http://dx.doi.org/10.2307/3250961

Bandura, A. (1977). Social Learning Theory. Englewood Cliffs, N.J.: Prentice-Hall.

Chantarasombat, C. (2007). Development of Knowledge Management Model for Community Organization (Master of education thesis, Mahasarakam: Mahasarakam University).

Chantarasombat, C. (2008). Participatory Action Research for Community Development (2nd ed.). Khon Kaen: Klangnanawittaya.

Chantarasombat, C. (2010). Knowledge Management and School Administration into Learning Organization. Mahasarakam: Faculty of Education, Mahasarakam University.

Chantarasombat, C., Srisa-ard, B., Kuofie, M., \& Jennex, M. (2010). Using Knowledge Management to Create Self-Reliant Communities in Thailand. International journal of Knowledge Management, 6(1), 62-78. http://dx.doi.org/10.4018/jkm.2010103004

Chanthtarasombat, C. (2009). Development a Knowledge Management Model for Self-Reliant Communities. Medwell Journals, 4(4), 392-396.

Cook, S., \& Brown, J. S. (1999). Bridging Epistemologies: The Generative Dancebetween Organizational Knowledge and Organizational Knowing. Organization Science, 10(4).

Groff, R. T., \& Jones, P. T. (2003). Introduction to Knowledge Management. Amsterdam: Butterworth Heinemann.

Jennex, M. E. (2005). What is knowledge management? International journal of Knowledge Management, 1(4), 4-5.

Jennex, M. E., \& Smolnik, S. (2011). Strategies for Knowledge Management Success: Exploring Organizational Efficacy. New York: Information Science Reference. http://dx.doi.org/10.4018/978-1-60566-709-6 
Jennex, M. E., \& Zakharova, I. (2005). An Introduction to Knowledge and Knowledge Management. Retrieved from http://www.management.com.ua/strategy/str108.html

Mabintree, S. (2007). A world transformed:The new definition of wealth. Bangkok: May.

Ministry of Education. (2008). Basic Education Core Curriculum 2008. Bangkok: Community Agricultural Cooperatives of Thailand.

Nonaka, I., \& Takeuchi, H. (1995). The Knowledge-creating Company: How Japanese Companies Create the Dynamics of Innovation. New York: Oxford University Press.

Panich, W. (2005). Knowledge Management: Practitioner Issue. Bangkok: The Institute Promoting the Knowledge Management for Society (IKS).

Phaynoi, N. (2003). The removing lessons KM: farming in sustainable agriculture. The annual KM Thailand.Bangkok: Usa print.

Prawet, W. (2002). Knowledge Management. Reform Journal, 5(5), 74-76.

Ramasoota, P. (1997). Participatory Action Research (1st ed.). Bangkok: P.A. Living.

Russ, M. (2010). Knowledge Management Strategies for Business Development (pp. 2-9). New York: Business Science Reference. http://dx.doi.org/10.4018/978-1-60566-348-7

Sangkeap, T. (2012). Sustainable Development. Bangkok: V. print.

Sary, S., Chantarasombat, C., \& Siristhi, C. (2011). Knowledge Management (KM) Model Development for Community Health. International Journal of Educational Administration and Development, 2(1), 82-99.

Sinlaratana, P. (2006). Septem stone: 7 major reasons for change through education into the knowledge economy. Bangkok: Chulalongkorn University.

Tongho, R. (2008). Development of Tourism Network by Community through Participatory Action Research in Central Region Provinces. Bangkok: RamkamhangUniversity.

Wiig, K. (1993). Knowledge Management foundations. Arlington, TX: Schema Press.

Wijan, B. (2007). Knowledge Management, Intelligence, into Practice (3rd ed.). York: Thamkamon.

Wongvanich, S. (2009). An Accelerated Project for Building Good Character of Thai Children and Youth (3rd ed.). Bangkok: Graphic capsicum.

\section{Copyrights}

Copyright for this article is retained by the author(s), with first publication rights granted to the journal.

This is an open-access article distributed under the terms and conditions of the Creative Commons Attribution license (http://creativecommons.org/licenses/by/3.0/). 